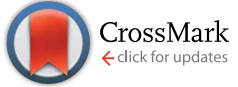

Cite this: RSC Adv., 2017, 7, 12247

Received 28th November 2016 Accepted 3rd February 2017

DOI: $10.1039 / c 6 r a 27417 j$

rsc.li/rsc-advances

\section{An investigation of chitosan and its derivatives on red blood cell agglutination $\dagger$}

\begin{abstract}
Xuan Zhou, Xinshuo Zhang, Jianjun Zhou* and Lin Li*
6-Deoxy-6-(2-aminoethyl) amino chitosan (CS-AEA) and aminoethyl modified CS-AEA (CS-AEA-AEM) were synthesized and characterized using FTIR, NMR and elemental analysis. The results showed that the expected CS derivatives were obtained, and the amine group content increased successively in CS, CS-AEA and CSAEA-AEM. The red blood cell (RBC) agglutination behaviors in solutions of CS and its derivatives were studied using optical microscopy (OM) and ultraviolet-visible (UV-Vis) spectrophotometry. The results demonstrated that the agglutination of RBCs became more evident upon decreasing the $\mathrm{pH}$ value and increasing the concentration. Although CS-AEA-AEM had the highest content of amine groups, CS-AEA exhibited the best agglutination performance under the $\mathrm{pH}$ and concentration range studied. Potentiometric titration and ionization degree calculations showed that the agglutination behavior of RBCs was determined by the number of protonated amines in CS or its derivatives. Hemocompatibility tests showed that the hemolysis of CS derivatives increased after modification, and the CS derivatives could be classified as a slightly hemolytic material. We have sucessfully developed a CS derivative (CS-AEA) with very good RBC agglutination performance under neutral conditions.
\end{abstract}

\section{Introduction}

Chitosan (CS) is a linear polymer derived from the $N$-deacetylation of chitin extracted from crustacean shells. It is composed of $\beta$-(1-4)-linked D-glucosamine and $N$-acetyl-D-glucosamine units. CS is a semi-crystalline polysaccharide and normally does not dissolve in aqueous solutions above $\mathrm{pH}$ 7.0. However, in dilute acids, the free amino groups in the D-glucosamine repeating unit can be protonated. Then, this polysaccharide becomes a polyelectrolyte, and solubilization occurs due to electrostatic repulsion. ${ }^{\mathbf{1 , 2}}$ As a type of natural biopolymer, CS has been widely utilized in areas including drug delivery, tissue engineering, cosmetics and food industries ${ }^{3-9}$ due to its superior biocompatibility, biodegradability, low toxicity, and antimicrobial activity. ${ }^{\mathbf{1 0 - 1 7}}$

It is widely reported that CS is an effective hemostatic agent because of its unique properties, which can accelerate wound healing in several clinical cases. ${ }^{18-20}$ Whole blood rapidly forms a coagulum once treated with a CS acetic acid solution..$^{21,22}$ The hemostatic properties of CS in solution are possibly due to its interaction with RBCs, which are linked together to establish a cellular clot or hemostatic plug. ${ }^{23,24}$ In addition to a chitosan solution, several chitosan-based dressings have been produced such as films, ${ }^{25,26}$ porous sponges ${ }^{27,28}$ and lyophilized bandages. ${ }^{29-31}$

Beijing Key Laboratory of Energy Conversion and Storage Materials, College of Chemistry, Beijing Normal University, Beijing 100875, China.E-mail: pla_zjj@bnu. edu.cn

† Electronic supplementary information (ESI) available. See DOI: 10.1039/c6ra27417j
As the main component of these dressings, chitosan salts can improve the hemostatic efficacy by enriching the RBCs. Other CS devices in the solid state like celox powder have also been used for hemostasis. ${ }^{32,33}$ It is important to mention that such powder needs to be poured onto haemorrhaging wounds and then covered with pressure dressings when used. No matter what form of CS exists in, the haemostatic mechanism of CS involves the agglutination of RBCs independent of the classical coagulation cascade. ${ }^{34,35}$ Briefly, glucosamine on CS is positively charged, which attracts the negatively-charged RBCs to agglutinate and therefore, promote clotting.

When glucosamine on CS is positively charged, acidic conditions should be provided. The acidic conditions will irritate the wound when CS is used as hemostatic material. Hence, in this manuscript, we would like to develop a CS derivative with very good RBCs agglutination performance under neutral conditions by synthesizing CS derivatives with different quantities of amino groups. Since the quantity of amino groups on CS is the key factor for its hemostatic properties, the effect of the amino group content on RBCs agglutination was also investigated at the same time.

\section{Experimental}

\subsection{Materials}

CS (deacetylation degree $80 \%$ and viscosity average molecular weight $\left.\left(\bar{M}_{\mathrm{v}}\right)=904 \mathrm{kDa}\right)$ was purchased from Nantong Xingcheng Biological Industrial Limited Co., China. Dialysis tubing (Viskase) with a molecular weight cut-off of $3.5 \mathrm{kDa}$ was used to 
purify the different chitosan derivatives. 2-Aminoethyl chloride hydrochloride with a purity of $98.0 \%$ was purchased from J\&K Scientific Ltd. Triphenylphosphine with purity higher than $99 \%$ was purchased from Aladdin Industrial Corporation. Hydrazine hydrate was obtained at chemical pure reagent grade and other chemicals were analytical grade reagents.

Rabbit whole blood anticoagulated with $3.8 \%$ (w/v) sodium citrate was obtained from Guangzhou Ruite Biotechnology Co., LTD.

Phosphate buffered saline (PBS) at pH 7.4 was prepared with $\mathrm{NaCl}, 0.2 \mathrm{M}$ disodium hydrogen phosphate and $0.2 \mathrm{M}$ sodium dihydrogen phosphate in a $250 \mathrm{~mL}$ volumetric flask. The volume ratio of $0.2 \mathrm{M}$ disodium hydrogen phosphate and $0.2 \mathrm{M}$ sodium dihydrogen phosphate was $81: 19$. The concentration of $\mathrm{NaCl}$ and sodium phosphate was $0.125 \mathrm{M}$ and $0.01 \mathrm{M}$, respectively. For $\mathrm{PBS}$ at $\mathrm{pH} 8.4$, the volume ratio of $0.2 \mathrm{M}$ disodium hydrogen phosphate and $0.2 \mathrm{M}$ sodium dihydrogen phosphate was $49: 1$.

\subsection{Synthesis}

The target compounds were synthesized according to Scheme 1.

Synthesis of $\boldsymbol{N}$-phthaloyl chitosan (PHCS). Phthaloylation of CS $(2.0 \mathrm{~g})$ was performed in $\mathrm{DMF} / \mathrm{H}_{2} \mathrm{O}(95 / 5)$ with a certain amount of phthalic anhydride, and the mixture was heated under a nitrogen atmosphere at $120{ }^{\circ} \mathrm{C}$ with stirring. After reacting for $8 \mathrm{~h}$, the mixture became a clear and viscous solution. The final mixture was cooled to room temperature and was precipitated with acetone. The precipitate was collected by filtration, washed several times with ethanol and then dried in an oven at $60{ }^{\circ} \mathrm{C}$ to obtain PHCS (2.46 g, yield: $\left.82 \%\right)$.

Synthesis of 6-deoxy-6-bromo- $\mathrm{N}$-phthaloyl chitosan (PHCSBr). PHCS (1.7 g, $5.9 \mathrm{mmol})$ was suspended in $N$-methyl pyrrolidone (NMP, $100 \mathrm{~mL}$ ). The solution was stirred under cooling in an ice-water bath. Triphenylphosphine $(15.15 \mathrm{~g}, 57.5 \mathrm{mmol})$ and $\mathrm{N}$-bromosuccinimide $(10.25 \mathrm{~g}, 57.5 \mathrm{mmol})$ in NMP $(70 \mathrm{~mL})$ was added in sequence at $0{ }^{\circ} \mathrm{C}$. After that, the mixture was gradually heated to $80^{\circ} \mathrm{C}$, stirred under a nitrogen atmosphere for $2 \mathrm{~h}$, and then precipitated with ethanol. The resulting precipitate was filtered and washed several times with ethanol. The residue

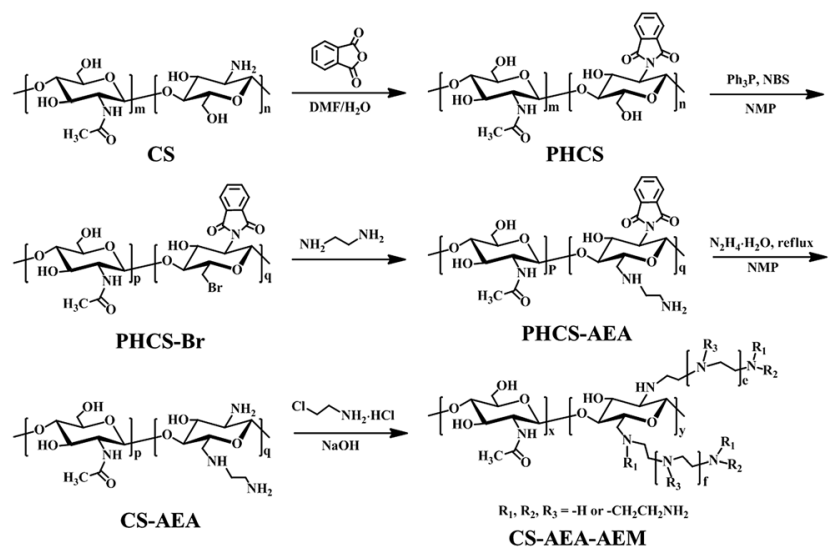

Scheme 1 The procedures used to synthesize CS-AEA and CS-AEAAEM. was stirred in ethanol at room temperature for $2 \mathrm{~h}$, filtered, washed again several times with ethanol and then dried in a vacuum oven at $60{ }^{\circ} \mathrm{C}$ to obtain PHCS-Br (1.66 g, yield: $78 \%$ ). The bromination degree of conversion on $-\mathrm{OH}$ substitution was around $55 \%$.

Synthesis of 6-deoxy-6-(2-aminoethyl) amino- $N$-phthaloyl chitosan (PHCS-AEA). Ethylenediamine $(26 \mathrm{~mL})$ was added to PHCS-Br (1 g) under stirring. The solution was heated and reacted for $7 \mathrm{~h}$ at $50{ }^{\circ} \mathrm{C}$ under $\mathrm{N}_{2}$. The mixture was dispersed with $50 \mathrm{~mL}$ of ethanol, which was centrifuged and further washed with ethanol and water, and then lyophilized to obtain PHCS-AEA (0.61 g, yield: 60\%).

Synthesis of 6-deoxy-6-(2-aminoethyl) amino chitosan (CSAEA). In order to remove phthalic anhydride from the $\mathrm{C}_{2}$ position of CS, PHCS-AEA (1.0 g) was suspended in NMP $(50 \mathrm{~mL})$, treated with hydrazine $(50 \mathrm{~mL})$, and gently heated at reflux for $4 \mathrm{~h}$. After cooling to room temperature, the reaction mixture was poured into $100 \mathrm{~mL}$ of ethanol. The CS-AEA product was collected as a yellow solid by centrifugation, thoroughly washed with ethanol, and then lyophilized. CS-AEA can gel instantly when in contact with water ( $0.38 \mathrm{~g}$, yield: $\left.56 \%, \bar{M}_{\mathrm{v}}=222 \mathrm{kDa}\right)$.

Synthesis of aminoethyl modified CS-AEA (CS-AEA-AEM). CSAEA-AEM was prepared using Je's method with slight modification. $^{36}$ 1.0 M 2-aminoethyl chloride hydrochloride $(55 \mathrm{~mL})$ was added to CS-AEA $(3 \mathrm{~g})$ with stirring at $65{ }^{\circ} \mathrm{C} .1 .0 \mathrm{M}(55 \mathrm{~mL})$ $\mathrm{NaOH}$ was added dropwise and the reaction continued for $18 \mathrm{~h}$. The obtained solution was dialyzed against deionized water for 2 days and then lyophilized to obtain a yellow, water-soluble CSAEA-AEM powder $\left(2.84 \mathrm{~g}\right.$, yield: $\left.90 \%, \bar{M}_{\mathrm{v}}=163 \mathrm{kDa}\right)$.

\subsection{Characterization}

The composition variation of CS and its derivatives during synthesis were confirmed using FTIR (Nicolet AVATAR 360 ), ${ }^{1} \mathrm{H}$ NMR and ${ }^{13} \mathrm{C}$ NMR (Bruker AVANCE III, $500 \mathrm{MHz}$ ) spectroscopy and elemental analysis (Vario EL). Samples for FTIR were prepared as potassium bromide disks after being dried under a lamp for $30 \mathrm{~min}$. NMR samples were dissolved in $1 \% \mathrm{DCl} / \mathrm{D}_{2} \mathrm{O}$ (v/v) or DMSO and the chemical shifts reported in ppm.

CS and its derivatives were titrated according to some previous reports. ${ }^{37-39}$ Separately, samples $(50 \mathrm{mg})$ were dissolved in $25 \mathrm{~mL} \mathrm{HCl}$ solution $(0.100 \mathrm{~N})$ and purged by bubbling with $\mathrm{N}_{2}$ for $10 \mathrm{~min}$. During titration, nitrogen atmosphere was maintained over the sample, which was thermostated at $24^{\circ} \mathrm{C}$. Under continuous stirring, a $0.100 \mathrm{~N} \mathrm{NaOH}$ solution was added dropwise and the $\mathrm{pH}$ values were recorded every 5 min using a Mettler Toledo FE20 Precision $\mathrm{pH} / \mathrm{mV}$ meter.

\subsection{Hemostatic performance}

CS and its derivatives in solutions of various concentration were obtained by dissolving in $1 \%(\mathrm{v} / \mathrm{v})$ aqueous acetic acid. To evaluate the agglutination of RBCs in solutions of CS and its derivatives, a suspension of RBCs was first prepared. Anticoagulated rabbit blood was centrifuged at $400 \mathrm{~g}$ for $10 \mathrm{~min}$, and the supernatant was carefully removed and discarded. RBCs were washed three times with $\mathrm{PBS}$ ( $\mathrm{pH} 7.4$ ) at $4{ }^{\circ} \mathrm{C}$ and finally re- 
Table 1 The specific chemical constituents of all the samples

\begin{tabular}{llllll}
\hline Sample & $\begin{array}{l}\text { pH 8.4 PBS } \\
(\mathrm{mL})\end{array}$ & $\begin{array}{l}\text { Saline } \\
(\mathrm{mL})\end{array}$ & $\begin{array}{l}\text { Acetic acid 1\% } \\
(\mu \mathrm{L})\end{array}$ & $\begin{array}{l}\mathrm{B}^{a} \\
(\mu \mathrm{L})\end{array}$ & $\begin{array}{l}\text { RBCs } \\
(\mu \mathrm{L})\end{array}$ \\
\hline Control-1 & 2.9 & - & 50 & - & 50 \\
$\mathrm{~B}_{1}(7.4)$ & 2.9 & - & - & 50 & 50 \\
$\mathrm{~B}_{2}(7.4)$ & 2.9 & - & - & 50 & 50 \\
$\mathrm{~B}_{3}(7.4)$ & 2.9 & - & - & 50 & 50 \\
Control-2 & 1.9 & 1 & 50 & - & 50 \\
$\mathrm{~B}_{1}(7.0)$ & 1.9 & 1 & - & 50 & 50 \\
$\mathrm{~B}_{2}(7.0)$ & 1.9 & 1 & - & 50 & 50 \\
$\mathrm{~B}_{3}(7.0)$ & 1.9 & 1 & - & 50 & 50 \\
Control-3 & 0.9 & 2 & 50 & - & 50 \\
$\mathrm{~B}_{1}(6.4)$ & 0.9 & 2 & - & 50 & 50 \\
$\mathrm{~B}_{2}(6.4)$ & 0.9 & 2 & - & 50 & 50 \\
$\mathrm{~B}_{3}(6.4)$ & 0.9 & 2 & - & 50 & 50
\end{tabular}

${ }^{a} \mathrm{~B}: \mathrm{B}_{1}, \mathrm{~B}_{2}$ and $\mathrm{B}_{3}$ are solutions of CS, CS-AEA and CS-AEA-AEM, respectively. CS and its derivatives in solution at various concentrations $\left(0.5,0.8,1.0,2.0,3.0,4.0\right.$ and $\left.5.0 \mathrm{mg} \mathrm{mL}^{-1}\right)$ have been prepared.

suspended in PBS to obtain an RBCs suspension at 5\% (v/v) hematocrit.

To evaluate the RBCs agglutination behavior, in vitro studies were performed by incubating the RBCs in CS and its derivatives solution at $37^{\circ} \mathrm{C}$ for $30 \mathrm{~min}$. Three $\mathrm{pH}$ values $(7.4,7.0,6.4)$ were adjusted by saline and PBS (pH 8.4) and the specific composition of the sample solution is shown in Table 1. At the end of the incubation, $20 \mu \mathrm{L}$ of the solution was sampled and observed using optical microscopy (OM) (Olympus BX53) in phasecontrast mode and UV-Vis spectra (PerkinElmer Lambda 750) with absorbance at $540 \mathrm{~nm}$.

\subsection{Hemolysis}

The hemolysis of CS, CS-AEA, and CS-AEA-AEM was estimated by measuring the haemoglobin released from the RBCs. Samples were prepared according to Table 1 and incubated at $37{ }^{\circ} \mathrm{C}$ for $3 \mathrm{~h}$. Then, the mixtures were centrifuged at $1000 \mathrm{~g}$ for $5 \mathrm{~min}$. The absorbance of the supernatant was determined at $540 \mathrm{~nm}$ using a UV-Vis spectrophotometer. Distilled water and saline were used as the positive control and negative control, respectively. The hemolysis was calculated using the following equation:

$$
\text { Hemolysis }(\%)=\left(D_{\mathrm{s}}-D_{\mathrm{n}}\right) /\left(D_{\mathrm{P}}-D_{\mathrm{n}}\right) \times 100
$$

where $D_{\mathrm{s}}, D_{\mathrm{n}}$, and $D_{\mathrm{P}}$ are the absorbances of the sample, saline, and distilled water, respectively.

\section{Results and discussion}

\subsection{Synthesis and characterization of chitosan derivatives}

During the synthesis, the composition was monitored using FTIR spectroscopy. The FTIR spectra of CS, PHCS, CS-AEA and CS-AEA-AEM are shown in Fig. 1. CS showed a broad absorption band in the range of $3200-3500 \mathrm{~cm}^{-1}$, corresponding to $-\mathrm{OH}$ and $-\mathrm{NH}$ stretching vibrations; the bands at about $1659 \mathrm{~cm}^{-1}$

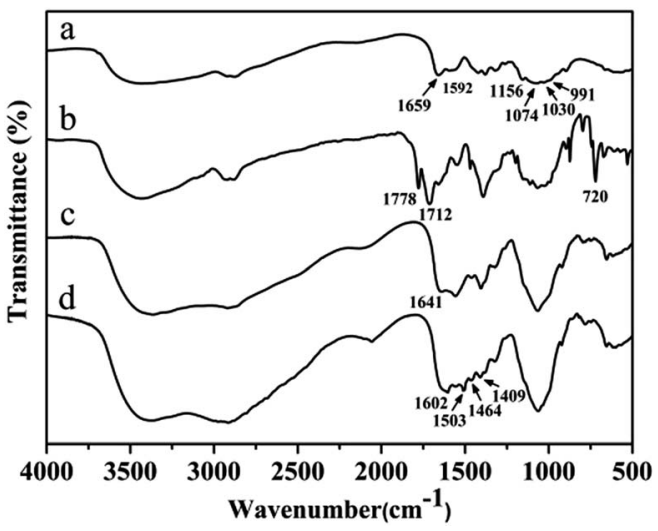

Fig. 1 The FTIR spectra of (a) CS, (b) PHCS, (c) CS-AEA and (d) CSAEA-AEM.

and $1592 \mathrm{~cm}^{-1}$ correspond to the $\mathrm{C}=\mathrm{O}$ stretching vibrations of the acetyl group (amine I) and $\mathrm{N}-\mathrm{H}$ bending vibrations (amine II) of the residual $N$-acetyl groups, respectively. The skeletal vibration of pyranose in CS (C-O-H) was located at 1156, 1074, 1030 and $991 \mathrm{~cm}^{-1} \mathbf{. 4 0 , 4 1}^{\mathbf{4}}$ After phthaloylation of CS, the FTIR spectrum of PHCS showed two bands at 1778 and $1712 \mathrm{~cm}^{-1}$, corresponding to the $\mathrm{C}=\mathrm{O}$ of the imide, which are the characteristic absorption bands of phthaloyl groups. ${ }^{42,43}$ A strong absorption band at $720 \mathrm{~cm}^{-1}$ was also found, which was responsible for the $\mathrm{C}-\mathrm{H}$ bending vibration of phenyl ring. These characteristic bands indicated the successful introduction of the phthaloyl group onto CS. CS-AEA showed an intensified band at around $1641 \mathrm{~cm}^{-1}$, which can be assigned to the transmutation vibration of $-\mathrm{NH}_{2} \cdot{ }^{44}$ The appearance of the band at $1641 \mathrm{~cm}^{-1}$ indicated that large quantities of $-\mathrm{NH}_{2}$ groups had been grafted onto CS. In addition, the disappearance of the characteristic peaks of the phthaloyl group and phenyl ring showed that the $N$-phthaloyl groups had been removed during the deprotection reaction. Evidence from the FTIR spectra indicated that ethylenediamine had been successfully grafted onto CS to form CS-AEA.

For CS-AEA-AEM, in addition to the transmutation vibration band of $-\mathrm{NH}_{2}\left(1602 \mathrm{~cm}^{-1}\right)$ and bending vibration band of $-\mathrm{NH}-$ $\left(1503 \mathrm{~cm}^{-1}\right)$, the scissor vibration band $\left(1464 \mathrm{~cm}^{-1}\right)$ and swing vibration $\left(1409 \mathrm{~cm}^{-1}\right)$ of $-\mathrm{CH}_{2}$ on $-\mathrm{CH}_{2}-\mathrm{N}-$ were also observed. ${ }^{\mathbf{4 4 , 4 5}}$ Given the complex structure of the CS derivatives and the overlapping of the characteristic bands observed in the FTIR spectra, the structure was further analyzed using NMR spectroscopy.

The ${ }^{1} \mathrm{H}$ NMR spectra of CS, PHCS, CS-AEA and CS-AEA-AEM are shown in Fig. 2. For CS, the peak at 4.76 ppm was assigned to $\mathrm{H} 1$, and the multiplets at 3.48-3.92 $\mathrm{ppm}$ were due to $\mathrm{H} 2^{\prime}, \mathrm{H} 3$, H4, H5 and H6 of CS. The Ha peak corresponds to the three protons of the acetyl group. For PHCS, the characteristic chemical shift peaks derived from CS in PHCS increased due to the introduction of the $N$-phthaloyl groups, which are the electron withdrawing groups. The peaks at 7.3-8.1 ppm are due to proton signals of the aromatic phthalimido groups, which disappear from CS-AEA after de-protection. In the ${ }^{1} \mathrm{H}$ NMR spectrum of CS-AEA, the peaks at 3.50 and 3.47 ppm were due to 


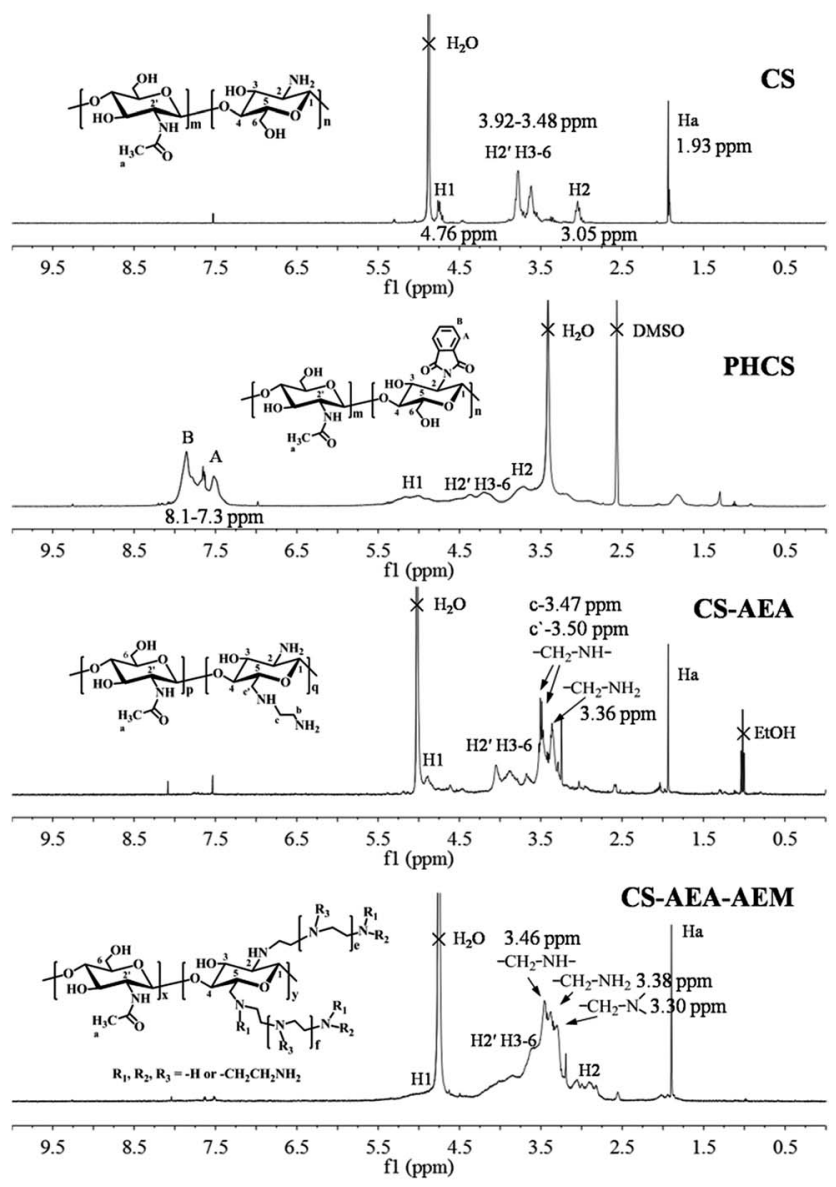

Fig. 2 The ${ }^{1} \mathrm{H}$ NMR spectra of CS, PHCS, CS-AEA and CS-AEA-AEM in $1 \%(\mathrm{v} / \mathrm{v}) \mathrm{DCl} / \mathrm{D}_{2} \mathrm{O}$ and $\mathrm{PHCS}$ in DMSO at $25^{\circ} \mathrm{C}$.

the proton signals of $-\mathrm{CH}_{2}-\mathrm{NH}-$, while the peak at $3.36 \mathrm{ppm}$ was due to the proton signal of $-\mathrm{CH}_{2}-\mathrm{NH}_{2}$. The signal at $\mathrm{H} 2$ was covered by the signal of the $-\mathrm{CH}_{2}-\mathrm{NH}_{2}$ groups. Given the similar local chemical environment in the ${ }^{1} \mathrm{H}$ NMR spectrum of CSAEA-AEM, the signals for the protons in the aminoethyl group and pyranoid ring were overlapped and appeared at 2.70$4.32 \mathrm{ppm}$. The peak at $3.46 \mathrm{ppm}$ was identified as the signal of $-\mathrm{CH}_{2}-\mathrm{NH}-$. The peak at $3.38 \mathrm{ppm}$ was assigned to the proton signals of $-\mathrm{CH}_{2}-\mathrm{NH}_{2}$. The peak at $3.30 \mathrm{ppm}$ was due to the signal of $-\mathrm{CH}_{2}-$ connected with tertiary amines.

The ${ }^{13} \mathrm{C}$ NMR spectra of CS, CS-AEA and CS-AEA-AEM are shown in Fig. S1 (ESI†). CS exhibits signals at 97.34, 76.27, $74.68,69.91,59.97$ and $55.75 \mathrm{ppm}$, which were assigned to C-1, C-4, C-5, C-3, C-6, and C-2 in the pyranoid ring, respectively. The peaks at 176.58 and $20.41 \mathrm{ppm}$ were assigned to C-7 and C-8 in the acetyl group, respectively. For CS-AEA, the peaks at 35.41 and $36.39 \mathrm{ppm}$ correspond to $-\mathrm{CH}_{2}-\mathrm{NH}_{2}$, while the peaks at 44.94 and $48.21 \mathrm{ppm}$ can be ascribed to the signals of $-\mathrm{CH}_{2}-$ $\mathrm{NH}-$ marked in the corresponding structural formula. Different from CS-AEA, the peaks at 47.62-51.94 ppm show the existence of different $-\mathrm{CH}_{2}$ - connected with the amines in the ${ }^{13} \mathrm{C}$ NMR spectrum of CS-AEA-AEM.

The elemental composition of CS and its derivatives were obtained using an organic element analyzer and the results are
Table 2 The results of the organic elemental analysis of CS and its derivatives

\begin{tabular}{lrrrr}
\hline Name & $\mathrm{N}(\%)$ & $\mathrm{C}(\%)$ & $\mathrm{H}(\%)$ & $\mathrm{N} / \mathrm{C}(\%)$ \\
\hline CS & 7.49 & 42.34 & 7.18 & 17.69 \\
CS-AEA & 15.59 & 45.44 & 8.48 & 34.31 \\
CS-AEA-AEM & 13.41 & 34.74 & 7.88 & 38.60
\end{tabular}

shown in Table 2. The N/C ratio can be used as an indication of the amine group content in the polymers and was $17.69 \%$, $34.31 \%$ and $38.60 \%$ in CS, CS-AEA and CS-AEA-AEM, respectively. It was clear that the amine group content increased successively, as expected.

\subsection{OM study of RBCs agglutination}

The interactions between RBCs and CS and its derivatives were evaluated using OM. To eliminate the effect of $\mathrm{pH}$ on RBCs agglutination, control samples without CS and its derivatives were prepared and no agglutination behavior was observed (Fig. S2, ESI†). In the control samples, RBCs did not agglutinate even after prolonged incubation. Therefore, without CS or its derivatives in the solution, changing the $\mathrm{pH}$ should have no influence on the agglutination of RBCs.

The agglutination behavior of RBCs in CS, CS-AEA and CSAEA-AEM solution at various $\mathrm{pH}$ values is shown in Fig. 3. At $\mathrm{pH}$ 7.4, no agglutination of RBCs was found in the CS solution (Fig. 3a), while evident agglutination of RBCs was observed in the CS-AEA and CS-AEA-AEM solutions (Fig. $3 \mathrm{~b}$ and c). At $\mathrm{pH}$ 7.0, RBCs began to agglutinate in the CS solution, and a small amount of agglutination with three to five RBCs together was found (Fig. 3d). A larger RBCs cluster was found in the CS-AEA solution (Fig. 3e), while no significant improvement in RBCs agglutination was found in the CS-AEA-AEM solution (Fig. 3f). At pH 6.4, RBCs agglutination became more evident (Fig. 3g-i).

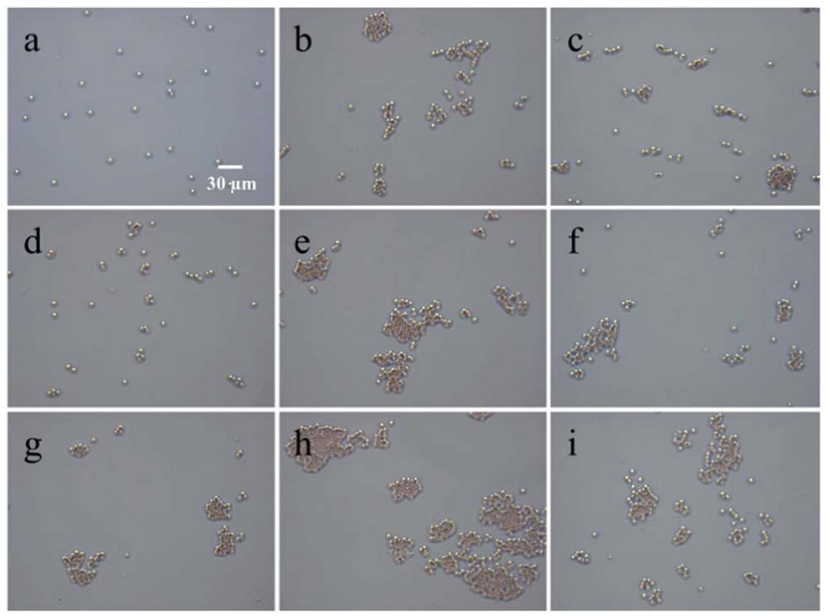

Fig. 3 OM images of RBCs agglutination in solutions of CS and its derivatives at a concentration of $4 \mathrm{mg} \mathrm{mL}^{-1}$. At pH 7.4: (a) CS, (b) CSAEA and (c) CS-AEA-AEM. At pH 7.0: (d) CS, (e) CS-AEA and (f) CS-AEAAEM. At pH 6.4: (g) CS, (h) CS-AEA and (i) CS-AEA-AEM. 


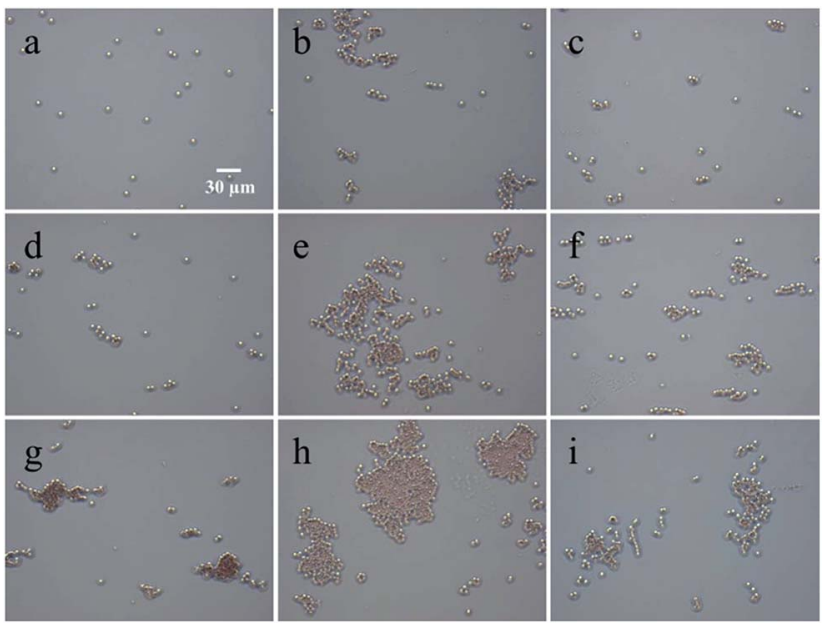

Fig. 4 OM images of RBCs agglutination in solutions of $C S$ and its derivatives at $\mathrm{pH}$ 6.4. At $0.8 \mathrm{mg} \mathrm{mL}^{-1}$ : (a) CS, (b) CS-AEA and (c) CSAEA-AEM. At $2.0 \mathrm{mg} \mathrm{mL}^{-1}$ : (d) CS, (e) CS-AEA and (f) CS-AEA-AEM. At $5.0 \mathrm{mg} \mathrm{mL}^{-1}$ : (g) CS, (h) CS-AEA and (i) CS-AEA-AEM.

Clusters were found in the CS solution, and very large agglutination clusters were formed in the CS-AEA solution. It could be found that for CS and its derivatives, the agglutination degree of RBCs increased with a decrease in the $\mathrm{pH}$ value.

The effect of concentration on RBCs agglutination was further investigated. As shown in Fig. 4, the agglutination of RBCs became evident as the concentration of CS and its derivatives was increased at $\mathrm{pH}$ 6.4. In the $\mathrm{CS}$ solution, when the concentration was $0.8 \mathrm{mg} \mathrm{mL}^{-1}$, RBCs were randomly dispersed in the solution and no agglutination was observed (Fig. 4a). As the concentration increased to $2.0 \mathrm{mg} \mathrm{mL}^{-1}$, loose agglutination was found occasionally (Fig. 4d). When the concentration was further increased to $5.0 \mathrm{mg} \mathrm{mL}{ }^{-1}$, a large cluster of RBCs agglutination was observed (Fig. 4g). In the CS-AEA solution, agglutination was found even at $0.8 \mathrm{mg} \mathrm{mL}^{-1}$ (Fig. 4b). As the concentration increased, agglutination became more evident (Fig. 4e), and tight large clusters of RBCs were found as the concentration reached $5.0 \mathrm{mg} \mathrm{mL}^{-1}$ (Fig. $4 \mathrm{~h}$ ). In the CS-AEAAEM solution, agglutination was also found at $0.8 \mathrm{mg} \mathrm{mL}^{-1}$ (Fig. 4c). An increase in the degree of agglutination was also found upon increasing the CS-AEA-AEM concentration (Fig. 4f and i). Similar phenomena can also be observed at $\mathrm{pH}=7.0$ and $\mathrm{pH}=7.4$ (Fig. S3 and S4, ESI†).

The microscopy results indicated that CS and its derivatives can promote RBCs agglutination, which was affected by both the $\mathrm{pH}$ and concentration. A lower $\mathrm{pH}$ value and higher concentration of CS or its derivatives can enhance the RBCs agglutination behavior. When compared with CS and CS-AEAAEM, CS-AEA showed the best performance of promoting RBCs agglutination.

\subsection{Spectrophotometric study of RBCs agglutination}

The effect of CS and its derivatives on RBCs agglutination was further quantitatively studied using a spectrophotometric method, which measured the decrease in absorbance at $540 \mathrm{~nm}$ due to RBCs agglutination. ${ }^{46}$ The results are shown in Fig. 5 . The samples with no CS or its derivatives added were the control samples. It could be found that the control samples showed the maximum absorbance over all the $\mathrm{pH}$ values studied, which corresponds to no agglutination of RBCs in the solution. At $\mathrm{pH}$ $=7.4$, the absorbance did not change with the CS concentration, which meant that no or very weak interactions existed between CS and RBCs in an alkalescent solution (Fig. 5a). The absorbance of CS-AEA and CS-AEA-AEM began to decrease as the concentration increased to more than $1 \mathrm{mg} \mathrm{mL}^{-1}$. The absorbance of CS-AEA decreased at a much more rapid rate than that of CS-AEA-AEM at a concentration ranging from $1 \mathrm{mg} \mathrm{mL}^{-1}$ to $5 \mathrm{mg} \mathrm{mL}{ }^{-1}$. The absorbance reached 2.60 and 2.66 at
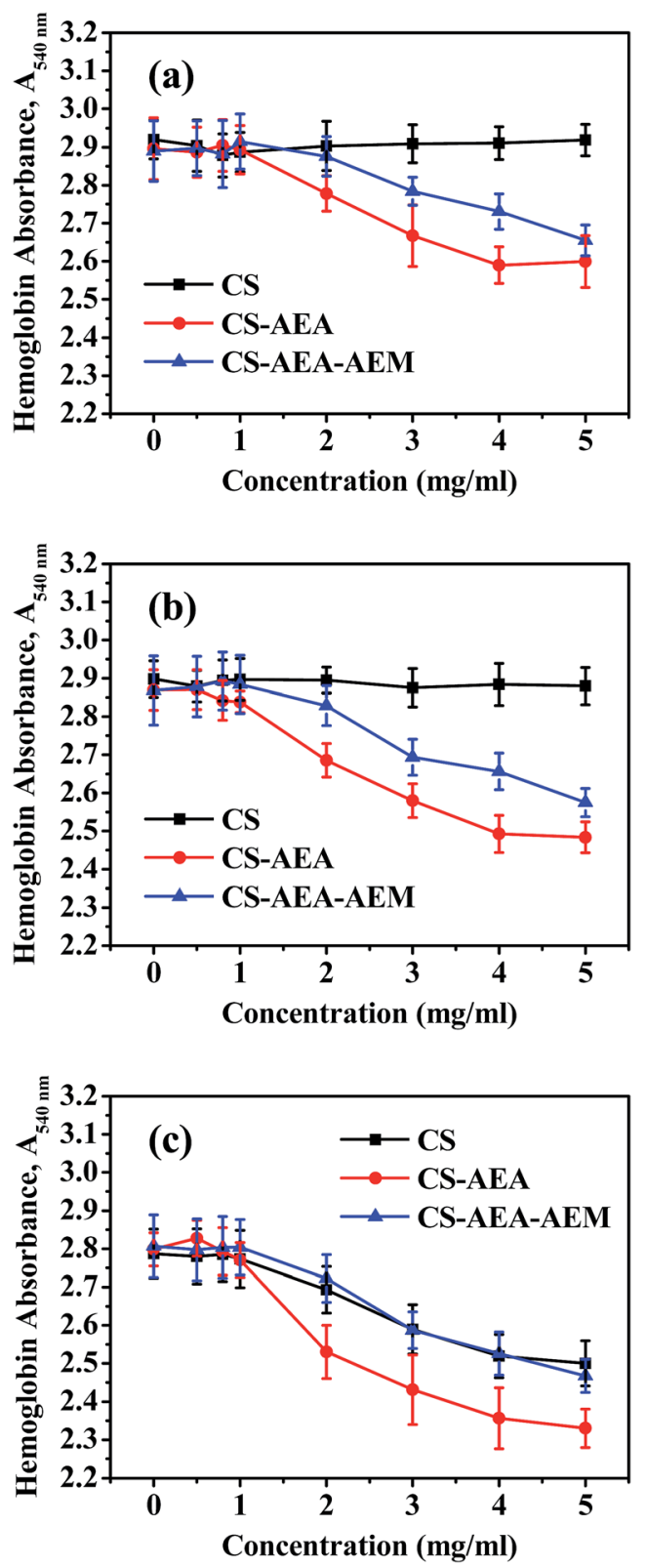

Fig. 5 Spectrophotometric measurements of the aggregation of RBCs with CS, CS-AEA and CS-AEA-AEM at a specific $\mathrm{pH}$ : (a) $\mathrm{pH}=7.4$, (b) $\mathrm{pH}$ $=7.0$ and $(\mathrm{c}) \mathrm{pH}=6.4$. 
a concentration of $5 \mathrm{mg} \mathrm{mL}^{-1}$ for CS-AEA and CS-AEA-AEM, respectively. The lower absorbance value indicated that more RBCs were agglutinated in the solution. At $\mathrm{pH}=7.0$, a similar trend was found for CS and its derivatives. The absorbance did not change in the CS solution and decreased in the CS-AEA and CS-AEA-AEM solutions (Fig. 5b). At $\mathrm{pH}=6.4$, the absorbance of CS and its derivatives showed the same changing trend, which significantly decreased upon increasing the concentration when the concentration was greater than $1 \mathrm{mg} \mathrm{mL}^{-1}$ (Fig. 5c). The absorbance values were 2.50, 2.33 and 2.47 for CS, CS-AEA and CS-AEA-AEM at a concentration of $5 \mathrm{mg} \mathrm{mL} \mathrm{m}^{-1}$, respectively. The evident decrease in absorbance at $\mathrm{pH} 6.4$ indicated that CS can promote RBCs agglutination under acidic conditions and CS's ability to promote RBCs agglutination was almost the same as CS-AEA-AEM. For the same polymer, the absorbance decreased with $\mathrm{pH}$. For example, the absorbance of CS-AEA was $2.60,2.48$ and 2.33 at $\mathrm{pH} 7.4,7.0$ and 6.4 , respectively. The decrease in absorbance indicated that the degree of agglutination increased as the $\mathrm{pH}$ value decreased. At the three $\mathrm{pH}$ values studied, the absorbance of CS-AEA was always the smallest at the same concentration, which means that CS-AEA had the best capability of promoting RBCs agglutination irrespective of the $\mathrm{pH}$ value. The spectrophotometric results were in good agreement with the OM observations. Although the content of amine group increased in CS-AEA-AEM, the capability of promoting RBCs agglutination did not increase as expected. To investigate how the amine groups affect RBCs agglutination, a potentiometric titration was carried out and the degree of ionization for the amine groups in CS and its derivatives was also calculated.

\subsection{Potentiometric titration and the degree of ionization}

Since different amines exhibit different basicity, a potentiometric titration was used to discriminate different types of amines in CS, CS-AEA and CS-AEA-AEM. The first order derivative curves of $\mathrm{pH} / \mathrm{V}$ are shown in Fig. 6a. The first inflection point in the curve corresponds to the neutralization of the excessive $\mathrm{HCl}$. CS showed two inflection points at $\mathrm{pH} 4.19$ and $9.26\left(V_{\mathrm{NaOH}}=22.75\right.$ and $25.10 \mathrm{~mL}$, respectively). The second inflection point at $\mathrm{pH} 9.26$ originates from $-\mathrm{NH}_{2} \cdot \mathrm{HCl}-$ neutralized by $\mathrm{NaOH}$. CS-AEA showed three inflection points at pH 3.66, 7.69 and $10.25\left(V_{\mathrm{NaOH}}=21.90,24.90\right.$ and $26.40 \mathrm{~mL}$, respectively). The inflection points at $\mathrm{pH} 7.69$ and 10.25 originated from $-\mathrm{NH}_{2} \cdot \mathrm{HCl}-$ and $-\mathrm{NH} \cdot \mathrm{HCl}-$ neutralized by $\mathrm{NaOH} .{ }^{47}$ CS-AEA-AEM also showed three main inflection points at $\mathrm{pH}$ 4.02, 7.48 and $10.41\left(V_{\mathrm{NaOH}}=24.05,26.80\right.$ and $29.50 \mathrm{~mL}$, respectively). In addition, the inflection points at $\mathrm{pH} 7.48$ and 10.41 originated from $-\mathrm{NH}_{2} \cdot \mathrm{HCl}-$ and $-\mathrm{NH} \cdot \mathrm{HCl}-$ neutralized by $\mathrm{NaOH}$. The consumption volumes of $\mathrm{NaOH}$ for $-\mathrm{NH}_{2} \cdot \mathrm{HCl}-$ and $-\mathrm{NH} \cdot \mathrm{HCl}-$ were $3.0 \mathrm{~mL}$ and $1.5 \mathrm{~mL}$ for CS-AEA and $2.75 \mathrm{~mL}$ and $2.70 \mathrm{~mL}$ for CS-AEA-AEM, respectively. From the potentiometric titration results, it could be calculated that the ratios of primary to secondary amine in CS-AEA and CS-AEA-AEM were around 2.00 and 1.02 , respectively. The results indicated that ethylenediamine had been successfully grafted onto CS to obtain CSAEA. Since the ratios of primary to secondary amine decreased
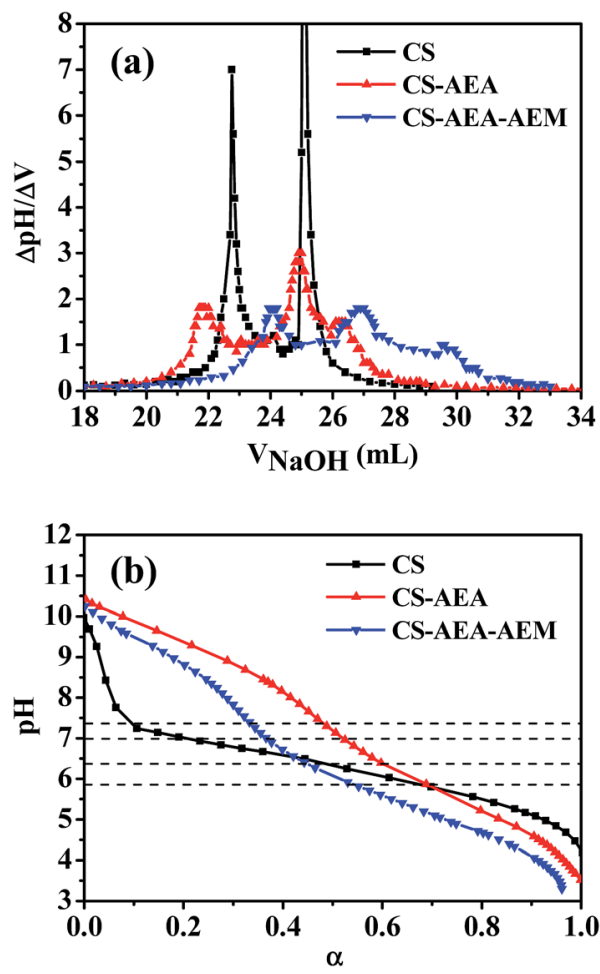

Fig. 6 Potentiometric titration of solutions of CS and its derivatives using $\mathrm{NaOH}$. (a) $\Delta \mathrm{pH} / \Delta V$ vs. $V_{\mathrm{NaOH}}$ and (b) $\mathrm{pH}$ vs. degree of ionization.

from 2.00 in CS-AEA to 1.02 in CS-AEA-AEM, the increased amine groups in CS-AEA-AEM should be secondary amines.

The degree of ionization $(\alpha)$ for the amines on CS and its derivatives was calculated according to the following equation: ${ }^{37,38}$

$$
\alpha=\frac{\left[\mathrm{Cl}^{-}\right]+\left[\mathrm{OH}^{-}\right]-\left[\mathrm{H}^{+}\right]-\left[\mathrm{Na}^{+}\right]}{[\text {amines }]}
$$

where [amines] is the total concentration of all the amine groups in the solution, which can be obtained according to the consumption of $\mathrm{NaOH}$ between the first inflection point and the last inflection point. $\alpha$ is the fraction of amine groups in solution that is positively charged.

The results are shown in Fig. 6b. Under neutral or alkaline conditions, CS-AEA had the highest $\alpha$, and the $\alpha$ values were in the order: $\alpha_{\text {CS-AEA }}>\alpha_{\text {CS-AEA-AEM }}>\alpha_{\text {CS }}$. This means that the amine groups on the CS derivatives were more easily protonated than those on CS under neutral or alkaline conditions. Although CSAEA-AEM had the highest content of amine groups, the ratio of protonated amine groups was not the highest. As the acidity increased, the $\alpha$ value of CS increased very rapidly. When the $\mathrm{pH}$ value was lower than 5.8, CS showed the highest $\alpha$ value at the same $\mathrm{pH}$. Our results demonstrate that the $\alpha$ value of the amines could be adjusted by changing the $\mathrm{pH}$. At $\mathrm{pH}$ 7.4, the $\alpha$ values were $0.09,0.33$ and 0.49 for CS, CS-AEA-AEM and CS-AEA, respectively. It was found that CS-AEA had the largest $\alpha$ value, while the $\alpha$ value was very small in the CS solution. At $\mathrm{pH} 7.0$, the $\alpha$ values were $0.19,0.37$ and 0.52 for CS, CS-AEA-AEM and CS-AEA, respectively. Although the $\alpha$ value of CS increased 


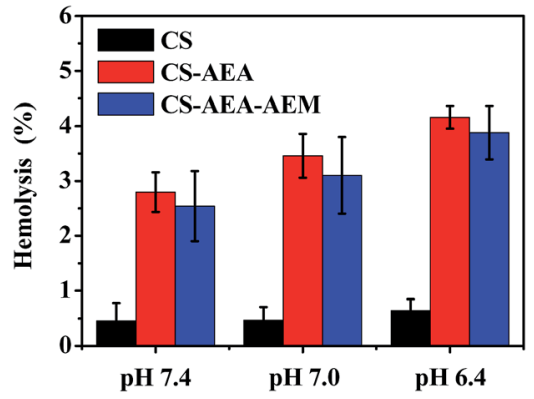

Fig. 7 Hemolysis of CS, CS-AEA and CS-AEA-AEM at a concentration of $5 \mathrm{mg} \mathrm{mL}^{-1}$.

significantly, it was still at a very low value. At $\mathrm{pH} 6.4$, the $\alpha$ values were $0.47,0.44$ and 0.60 for CS, CS-AEA-AEM and CS-AEA, respectively. The $\alpha$ value of $\mathrm{CS}$ reached 0.47 , and a large number of positively charged amine groups could be expected. The agglutination behavior of RBCs was affected by $\alpha$, which determined the number of protonated amine groups. The different $\alpha$ values in the solutions of CS and its derivatives should exert a diverse influence on RBCs agglutination under various $\mathrm{pH}$ conditions. In the CS solution, it was reasonable to observe RBCs agglutination at $\mathrm{pH}$ 6.4, while almost no agglutination was found at pH 7.0 and 7.4. At the same concentration, the higher $\alpha$ value led to more protonated amine groups in solution and then, more evident agglutination of RBCs, which was in accordance with our $\mathrm{OM}$ and spectrophotometric results.

\subsection{Hemolysis}

The hemocompatibility of the CS derivatives was evaluated, which is an important initial assessment of the toxic effect of biomaterials. As shown in Fig. 7, the hemolysis of CS, CS-AEA and CS-AEA-AEM increased with the decrease of $\mathrm{pH}$ value. They were $0.46 \%, 4.16 \%$ and $3.88 \%$, respectively at $\mathrm{pH} 6.4$. According to the ASTM standard F756, hemoglobin release of 0$2 \%, 2-5 \%$ or $>5 \%$ of the total release is classified as nonhemolytic, slightly hemolytic or haemolytic, respectively. After modification, the hemolysis of the CS derivatives was in the range of $2-5 \%$, which indicated that the CS derivatives were slightly hemolytic. Our results demonstrate that increasing the cationic amine group in CS increases haemoglobin release.

\section{Conclusions}

Two CS derivatives (CS-AEA and CS-AEA-AEM) have been designed and synthesized. FTIR and NMR spectroscopy verified that the expected CS derivatives were obtained. Elemental analysis showed that the amine group content increased successively, as expected. OM and UV-Vis spectrophotometry were used to study the RBCs agglutination behavior in solutions of CS and its derivatives. Similar results were obtained in which the agglutination of RBCs became more significant upon decreasing the $\mathrm{pH}$ and increasing the concentration. Although CS-AEA-AEM had the highest content of amine groups, CS-AEA exhibited the best agglutination performance over the $\mathrm{pH}$ and concentration range studied. The potentiometric titration results showed that the ratio of primary to secondary amines in CS-AEA and CS-AEA-AEM were around 2.00 and 1.02, respectively, which demonstrated that the increased amine groups were secondary amines. The results from calculating the degree of ionization showed that the degree of protonation of the amines can be adjusted by changing the $\mathrm{pH}$, which increased with a decrease in the $\mathrm{pH}$ value. The degree of ionization for the amine groups can explain the RBCs agglutination behavior very well at various $\mathrm{pH}$ values. Although the amine group content affected RBCs agglutination, the most important factor was the degree of ionization for the amine groups in the solutions of CS or its derivatives. A higher $\alpha$ value leads to more protonated amine groups in solution and then, more agglutination of RBCs. CS-AEA showed a high $\alpha$ value under the neutral conditions, which means that CS-AEA was a very good hemostatic material without irritation to the wound. The hemocompatibility tests showed that the hemolysis of the CS derivatives increased after modification, and the CS derivatives were slightly hemolytic. Our results will be helpful for developing hemostatic material based on CS.

\section{Acknowledgements}

This study was financially supported by the National Natural Science Foundation of China (Grant No. 21434003), the National High Technology Research and Development Program of China (863) (Grant No. 2015AA033801), the Fundamental Research Funds for the Central Universities, and the Program for Changjiang Scholars and Innovative Research Team in University and the National Science and Technology Major Project of the Ministry of China (Grant No. 2013ZX09J13110-11B).

\section{References}

1 M. Rinaudo, Polym. Int., 2008, 57, 397-430.

2 J. Carneiro, J. Tedim and M. G. S. Ferreira, Prog. Org. Coat., 2015, 89, 348-356.

3 M. de la Fuente, M. Ravina, P. Paolicelli, A. Sanchez, B. Seijo and M. J. Alonso, Adv. Drug Delivery Rev., 2010, 62, 100-117.

4 Z. Chen, L. Zhang, Y. Song, J. He, L. Wu, C. Zhao, Y. Xiao, W. Li, B. Cai and H. Cheng, Biomaterials, 2015, 52, 240-250.

5 L. W. Place, M. Sekyi, J. Taussig and M. J. Kipper, Macromol. Biosci., 2016, 16, 371-380.

6 K. T. Shalumon, K. H. Anulekha, K. P. Chennazhi, H. Tamura, S. V. Nair and R. Jayakumar, Int. J. Biol. Macromol., 2011, 48, 571-576.

7 S. M. Lee, K. H. Liu, Y. Y. Liu, Y. P. Chang, C. C. Lin and Y. S. Chen, Materials, 2013, 6, 1391-1402.

8 J. Dutta, S. Tripathi and P. K. Dutta, Food Sci. Technol. Int., 2012, 18, 3-34.

9 I. Hamed, F. Özogul and J. M. Regenstein, Trends Food Sci. Technol., 2016, 48, 40-50.

10 X. Ma, J. Ge, Y. Li, B. Guo and P. X. Ma, $R S C A d v .$, 2014, 4, 13652-13661.

11 A. Mellati, S. Dai, J. Bi, B. Jin and H. Zhang, RSC Adv., 2014, 4, 63951-63961. 
12 Z. K. Wang, Q. L. Hu and Y. X. Wang, Sci. China: Chem., 2011, 54, 380-384.

13 H. J. Lee and G. H. Kim, RSC Adv., 2012, 2, 7578-7587.

14 T. Kean and M. Thanou, Adv. Drug Delivery Rev., 2010, 62, 311.

15 B. Liu, S. Shen, J. Luo, X. Wang and R. Sun, RSC Adv., 2013, 3, 9714-9722.

16 Z. Jiang, H. Neetoo and H. Chen, J. Food Sci., 2011, 76, M22M26.

17 A. M. Diez-Pascual and A. L. Diez-Vicente, $R S C$ Adv., 2015, 5, 93095-93107.

18 K. Hagisawa, A. Saito, M. Kinoshita, T. Fujie, N. Otani, S. Shono, Y. K. Park and S. Takeoka, J. Vasc. Surg., 2013, 1, 289-297.

19 K. Azuma, R. Izumi, T. Osaki, S. Ifuku, M. Morimoto, H. Saimoto, S. Minami and Y. Okamoto, J. Funct. Biomater., 2015, 6, 104-142.

20 T. Dai, M. Tanaka, Y. Y. Huang and M. R. Hamblin, Antiinfective Therapy, 2011, 9, 857-879.

21 C. Beaulieu and A. Blais, WO2009061409A1, 2009.

22 W. G. Malette and H. J. Quigley, US4394373, 1981.

23 L. W. Chan, C. H. Kim, X. Wang, S. H. Pun, N. J. White and T. H. Kim, Acta Biomater., 2016, 31, 178-185.

24 H. Hattori and M. Ishihara, Biomed. Mater., 2015, 10, 015014. 25 A. El-Mekawy, S. Hudson, A. El-Baz, H. Hamza and K. ElHalafawy, J. Appl. Polym. Sci., 2010, 116, 3489-3496.

26 S. Lee, I. Jung, S. Yu and J. P. Hong, Archives of Plastic Surgery, 2014, 41, 466-471.

27 K. Kourelis and A. H. Shikani, Clin. Otolaryngol., 2012, 37, 309-313.

28 X. Huang, Y. Sun, J. Nie, W. Lu, L. Yang, Z. Zhang, H. Yin, Z. Wang and Q. Hu, Int. J. Biol. Macromol., 2015, 75, 322-329.

29 P. L. Kang, S. J. Chang, I. Manousakas, C. W. Lee, C. H. Yao, F. H. Lin and S. M. Kuo, Carbohydr. Polym., 2011, 85, 565570.

30 M. A. Brown, M. R. Daya and J. A. Worley, J. Emerg. Med., 2009, 37, 1-7.
31 M. Sanandam, A. Salunkhe, K. Shejale and D. Patil, Int. J. Adv. Biotechnol. Res., 2013, 4, 910-913.

32 A. H. Smith, C. Laird, K. Porter and M. Bloch, Emerg. Med. J., 2013, 30, 784-789.

33 J. Granville-Chapman, N. Jacobs and M. J. Midwinter, Injury, 2011, 42, 447-459.

34 S. B. Rao and C. P. Sharma, J. Biomed. Mater. Res., 1997, 34, 21-28.

35 P. R. Klokkevold, H. Fukayama, E. C. Sung and C. N. Bertolami, J. Oral Maxillofac. Surg., 1999, 57, 49-52.

36 J. Y. Je and S. K. Kim, Bioorg. Med. Chem., 2005, 13, 65516555.

37 E. F. Palermo, D. K. Lee, A. Ramamoorthy and K. Kuroda, J. Phys. Chem. B, 2011, 115, 366-375.

38 J. L. Thomas, H. You and D. A. Tirrell, J. Am. Chem. Soc., 1995, 117, 2949-2950.

39 A. Jintapattanakit, S. Mao, T. Kissel and V. B. Junyaprasert, Eur. J. Pharm. Biopharm., 2008, 70, 563-571.

40 C. Tapia, Z. Escobar, E. Costa, J. Sapag-Hagar, F. Valenzuela, C. Basualto, M. a. Nella Gai and M. Yazdani-Pedram, Eur. J. Pharm. Biopharm., 2004, 57, 65-75.

41 G. Ying, W. Xiong, H. Wang, Y. Sun and H. Liu, Carbohydr. Polym., 2011, 83, 1787-1796.

42 K. Kurita, H. Ikeda, Y. Yoshida, M. Shimojoh and M. Harata, Biomacromolecules, 2002, 3, 1-4.

43 S. I. Nishimura, O. Kohgo, K. Kurita and H. Kuzuhara, Macromolecules, 1991, 24, 4745-4748.

44 Y. Xie, X. Liu and Q. Chen, Carbohydr. Polym., 2007, 69, 142147.

45 X. Meng, R. Xing, S. Liu, H. Yu, K. Li, Y. Qin and P. Li, Int. J. Biol. Macromol., 2012, 50, 918-924.

46 H. S. Thatte, S. E. Zagarins, M. Amiji and S. F. Khuri, J. Trauma, 2004, 57, S7-S12.

47 J. Armstrong and R. B. Barlow, Br. J. Pharmacol., 1976, 57, 501-516. 